Check for updates

Cite this: RSC Adv., 2017, 7, 44933

Received 4th July 2017

Accepted 11th September 2017

DOI: $10.1039 / c 7 r a 07362 c$

rsc.li/rsc-advances

\section{Bimodal counterpropagating-responsive sensing material for the detection of histamine}

\author{
Zhengzong Wu, ${ }^{\text {ab }}$ Enbo Xu, ${ }^{a}$ Aiquan Jiao, ${ }^{a}$ Zhengyu Jin (D) *a and Joseph Irudayaraj ${ }^{\star b}$
}

Reliable and ultrasensitive quantification of harmful chemicals is essential to ensure food safety. In this study, a dual mode material for fast extraction and sensitive detection of histamine was developed. The novel sensing material was synthesized by coating a layer of molecularly imprinted polymers (MIPs) doped with silver nanoparticles (AgNPs) on the surface of upconversion particles (UCNPs). The novel material (UCNPs(MIPs-AgNPs) simultaneously possessed a positive surface-enhanced Raman scattering (SERS) response and negative fluorescence response. In the presence of histamine, the fluorescence intensity of UCNPs@MIPs-AgNPs was quenched gradually while the SERS intensity increased gradually. The limit of detection (LOD) and limit of quantitation (LOQ) of histamine were $0.009 \mathrm{mg} \mathrm{L}^{-1}$ and $0.02 \mathrm{mg} \mathrm{L}^{-1}$, and $0.04 \mathrm{mg} \mathrm{L}^{-1}$ and $0.1 \mathrm{mg} \mathrm{L}^{-1}$, respectively, under fluorescence mode and SERS mode. These results revealed that it is feasible to accurately detect histamine content by using the dual responsive material. The developed strategy integrates the advantages of upconverting nanotechnology, molecularly imprinted technology and SERS technology for highly specific enrichment and detection of histamine.

\section{Introduction}

Histamine, a common biogenic amine produced by bacterial decarboxylation from the amino acid histidine, acts to transmit signals from cell to cell in the skin, gut, and other organs of the immune system. ${ }^{1,2}$ It has been confirmed that the ingestion of excess histamine can trigger a wide array of symptoms including nausea, headache, diarrhea, oral numbness, palpitations, rashes, asthma and even death ${ }^{3-5}$ compromising health safety. In this context, histamine as the primary toxic compound existing in wine has attracted significant attention in food quality monitoring. Since conventional processing methods such as cooking and freezing cannot destroy histamine once it has formed, ${ }^{6}$ the continuous monitoring of trace levels of histamine in food products is essential.

Many methods have been developed for the detection of histamine, such as gas chromatography (GC), electrochemical sensing, ${ }^{8}$ capillary zone electrophoresis, ${ }^{9}$ thin layer chromatography (TLC),$^{10}$ high-performance liquid chromatography (HPLC) ${ }^{11}$ and enzyme-linked immunosorbent assay (ELISA). ${ }^{12}$ Although these conventional methods have the merits of high sensitivity and accuracy, they have several inherent drawbacks. Chromatographic methods are relatively sophisticated,

\footnotetext{
${ }^{a}$ The State Key Laboratory of Food Science and Technology, School of Food Science and Technology, Jiangnan University, 1800 Lihu Road, Wuxi 214122, China. E-mail: jinlab2008@yahoo.com; Fax: +86-510-85913299; Tel: +86-510-85913299

${ }^{b}$ Department of Bioengineering, College of Engineering, University of Illinois at Urbana-Champaign, Urbana, IL, USA 61820. E-mail: jirudaya@illinois.edu; Fax: +1217-300-0525; Tel: +1-217-300-0525
}

expensive and tedious. ELISA is strongly dependent on the use of unstable enzymes and expensive test kits, which cannot meet the high-throughput and quality control rigor required by the government and food industry. Thus, the exploitation of alternative rapid and accurate approach is of vital importance.

Spectroscopic methods are promising tools for the determination of toxic or harmful substances in food because they are inherently rapid, specific, and partially or completely computerized. ${ }^{13-16}$ The current fluorescence methods used in detection showed promise in the development of bioassay techniques, owing to its fast, sensitive and reproducible signal. Upconversion nanoparticles (UCNPs) doped with lanthanide have attracted tremendous attention. ${ }^{17-19}$ UCNPs can emit a high-energy photon at a shorter wavelength under excitation by multiple low-energy near-infrared (NIR) photons, instead of traditional photoexcitation in the UV or visible regions. As autofluorescence originating from coexisting substances in sample matrixes can be greatly minimized by the use of NIR photons, the background light interference and sensitivity of the detection can be improved with UCNPs-labeled optical sensing system with NIR as the excitation source.$^{20}$ In addition, UCNPs has good photochemical stability, large Stokes shifts, is nonblinking with deep penetration effects in biological samples and relatively low toxicity. All of these appealing advantages makes UCNPs a promising label compared to traditional fluorescent materials. ${ }^{21,22}$ Another promising spectroscopic technology is surface-enhanced Raman spectroscopy (SERS). SERS has become one of the most versatile quantitative approaches for detection even down to the single-molecule level. ${ }^{23,24}$ It has 
been successfully used as a rapid and accurate detection method for determining many kinds of chemical compounds or bacteria in food during the past decade..$^{25-27}$

Despite the tremendous progress made in the field of fluorescence and SERS detection technologies, challenges exist. In particular, the specific recognition of target molecule (i.e., selectivity) for separation-detection is difficult to achieve using traditional host guest chemistry in the sensor design. This has become a major challenge to the analytical utility. Here, sample pretreatment is essential to eliminate interferences to improve separation and detection and obtain satisfactory results. Molecular imprinting offers a new technique for efficient separation and enrichment of specific analytes from complicated matrices. It is a kind of biomimic technique to synthesize molecularly-imprinted polymers (MIPs) with artificially generated recognition sites that are able to specifically rebind a target molecule in preference to other closely-related compounds. ${ }^{28}$ MIPs synthesis is relatively cheap and easy, making it an excellent alternative to natural receptors. Because of these advantages, MIPs has attracted considerable attention and has been integrated with HPLC, quantum dots and graphene oxide for the determination of food chemical hazards in recent years. ${ }^{29,30}$ Feng et al. ${ }^{31}$ and $\mathrm{Hu}$ et al..$^{32}$ had successfully combined MIPs and SERS for accurate and high-throughput detection of melamine and $\alpha$-tocopherol in milk and vegetable oils, respectively. To the best of our knowledge, very few attempts have integrated MIPs and SERS or UCNPs in a single sensor system for separation and detection of histamine in food samples.

The current study aims to develop a novel sensor material for dual mode ultrasensitive detection of histamine by integrating the selective recognition ability of MIPs and the high detection sensitivity and accuracy of UCNPs and SERS technologies.

\section{Materials and methods}

\subsection{Chemicals and reagents}

Histamine, putrescine, $\beta$-phenylethylamine, spermine, spermidine, tryptamine, tyramine, cadaverine, ethylene glycol dimethacrylate (EGDMA), ammonium fluoride, $\boldsymbol{\alpha}$-methacrylic acid (MAA), 2,2'-azobis(isobutyronitrile) (AIBN) and poly(acrylic acid) (PAA, M.W. 2000) were obtained from Sigma-Aldrich (Saint Louis, MO, USA). Chloroform, ammonium acetate and sodium borohydride were from TCI Co., Ltd. (Portland, OR, USA). Ammonium fluoride $\left(\mathrm{NH}_{4} \mathrm{~F}\right)$, ethanol, sodium hydroxide, methanol and sodium chloride were purchased from Fisher Scientific (Waltham, MA, USA). Glutaraldehyde, (3-aminopropyl) triethoxysilane (APTES), 1,6-hexanediamine and octadecene (ODE), tetraethyl orthosilicate (TEOS), oleic acid (OA), ytterbium(III) chloride hexahydrate $\left(\mathrm{YbCl}_{3}\right)$, yttrium(III) chloride hexahydrate $\left(\mathrm{YCl}_{3}\right)$ and erbium chloride hexahydrate $\left(\mathrm{ErCl}_{3}\right)$ were all obtained from Alfa Aesar Co., Inc. (Tewksbury, MA, USA). Rice wine and red wine were purchased from Better World Market (West Lafayette, IN, USA). Canned tuna was purchased from Meijer Market (West Lafayette, IN, USA). All reagents and solvents used were analytical or HPLC grade. Deionized (DI) water $\left(18.2 \mathrm{M} \Omega \mathrm{cm}^{-1}\right)$ was prepared by the Millipore system (Billerica, MA, USA).

\subsection{Reference method for histamine determination}

Histamine content was determined by the method of Gao et al. ${ }^{4}$ Typically, a HPLC system (Agilent 1100 series, Germany) coupled with quaternary pump and a diode array detector was used to determine the concentration of histamine, with the use of a HILIC column (Luna@HILIC, $3 \mathrm{~mm}, 100 \times 2 \mathrm{~mm}$, Phenomenex, Torrance, CA, USA). The flow rate was $0.4 \mathrm{~mL} \mathrm{~min}^{-1}$ and mobile phase was consisted of ammonium acetate $(5 \mathrm{mM})$ and acetonitrile $(1: 9, \mathrm{v} / \mathrm{v})$.

\subsection{Synthesis of dual signal response material}

2.3.1. Preparation of UCNPs. In this work, oleic acidcapped UCNPs (OA-UCNPs) were synthesized using a previously reported solvothermal method with slight modifications. ${ }^{17}$ Briefly, $0.2366 \mathrm{~g}$ of $\mathrm{YCl}_{3} \cdot 6 \mathrm{H}_{2} \mathrm{O}(0.78 \mathrm{mmol}), 0.0774 \mathrm{~g}$ of $\mathrm{YbCl}_{3} \cdot 6 \mathrm{H}_{2} \mathrm{O}(0.20 \mathrm{mmol})$ and $0.0076 \mathrm{~g}$ of $\mathrm{ErCl}_{3} \cdot 6 \mathrm{H}_{2} \mathrm{O}$ $(0.02 \mathrm{mmol})$ were dissolved in $5 \mathrm{~mL}$ OA and $15 \mathrm{~mL}$ ODE in a $100 \mathrm{~mL}$ three-necked flask. The mixture was heated to $160{ }^{\circ} \mathrm{C}$ for $30 \mathrm{~min}$ to form a homogeneous yellow solution, and cooled down naturally to room temperature. Then $10 \mathrm{~mL}$ of methanol solution containing $0.1000 \mathrm{~g} \mathrm{NaOH}$ and $0.1480 \mathrm{~g} \mathrm{NH}_{4} \mathrm{~F}$ was slowly added to the flask, followed by stirring at $30{ }^{\circ} \mathrm{C}$ for $1 \mathrm{~h}$ to consume all fluoride. Subsequently, the solution was heated to $100{ }^{\circ} \mathrm{C}$ and maintained for $15 \mathrm{~min}$, ensuring that the methanol was removed completely. Then the solution was heated up to $300{ }^{\circ} \mathrm{C}$ and kept for $1 \mathrm{~h}$ under an argon atmosphere. After cooling to room temperature, the nanocrystals were obtained by centrifugation at $5000 \mathrm{rpm}$. The precipitate from the solution was washed with ethanol/cyclohexane mixture $(1: 1 \mathrm{v} / \mathrm{v})$ three times. Finally, the obtained UCNPs were dried overnight in a vacuum oven at $60{ }^{\circ} \mathrm{C}$. OA-UCNPs were thus formed and kept in a desiccator until ready to use.

The surface modification of the OA-UCNPs was performed using a ligand exchange with PAA. ${ }^{33}$ Typically, $30 \mathrm{mg}$ of the OAcapped UCNPs in chloroform $(4 \mathrm{~mL})$ were slowly added to a water solution $(8 \mathrm{~mL}$ ) containing $200 \mathrm{mg}$ PAA, and the solution was vigorously stirred for $24 \mathrm{~h}$. After that, the resultant solution was transferred into the upper water layer from the chloroform layer due to the PAA attachment. The nanoparticles were separated by centrifugation and washed three times with ultrapure water to obtain PAA-stabilized UCNPs.

2.3.2. Synthesis of UCNPs@MIPs-AgNPs. UCNPs@MIPsAgNPs was prepared as follows: $1 \mathrm{mmol}$ of histamine (template), $0.25 \mathrm{~g}$ of UCNPs and $4 \mathrm{mmol}$ of MAA (functional monomer) were dissolved in a mixture of $2 \mathrm{~mL}$ tetrahydrofuran and $3 \mathrm{~mL}$ methanol in a $50 \mathrm{~mL}$ flask. After the solution was mechanically stirred for $10 \mathrm{~min}$ before the addition of $4 \mathrm{mmol}$ of EGDMA (cross-linker) and incubated in oil bath overnight at $50{ }^{\circ} \mathrm{C}, 500 \mathrm{mg} \mathrm{AgNO}_{3}$ (AgNPs precursor) and $30 \mathrm{mg}$ of AIBN (free-radical initiator) were added to the flask, followed by purging with a gentle flow of nitrogen for $15 \mathrm{~min}$. Subsequently, the flask was sealed and placed in an oil bath at $70{ }^{\circ} \mathrm{C}$ for $24 \mathrm{~h}$. The product was ground to powder and sieved through a 200 mesh steel sieve to obtain homogeneous fine particles. Then, excessive $\mathrm{NaBH}_{4}$ was added to reduce UCNPs@MIPs-AgNO into UCNPs@MIPs-AgNPs. Afterward, histamine was removed 
by Soxhlet extraction with methanol/acetic acid $(8: 2, \mathrm{v} / \mathrm{v})$ solution until no histamine could be detected using HPLC. UCNPs@MIPs-AgNPs was then vacuum-dried at $60{ }^{\circ} \mathrm{C}$ and ground to powder with a mortar and pestle. As a reference, the non-molecular imprinted polymer (UCNPs@NIPs-AgNPs) was prepared using the same protocol without the addition of the template molecule (histamine).

\subsection{Evaluation of the binding capacities of UCNPs@MIPs- AgNPs and UCNPs@NIPs-AgNPs}

For the static adsorption tests, histamine was dissolved in $2 \mathrm{~mL}$ of ammonium acetate solution ( $30 \mathrm{mM}$ ) to form standard solutions with different concentrations $(10,25,50,75,100,150$ and $200 \mathrm{mg} \mathrm{L}^{-1}$, which were mixed with $10 \mathrm{mg}$ of UCNPs@MIPs-AgNPs or UCNPs@NIPs-AgNPs. Then, the mixtures were shaken in a thermostatic water bath oscillator at $200 \mathrm{rpm}$ for $45 \mathrm{~min}\left(25^{\circ} \mathrm{C}\right)$ and centrifuged at $5000 \times g$ for $15 \mathrm{~min}$. The resulting supernatant was filtered through a membrane filter (pore size: $0.45 \mu \mathrm{m}$ ) and the concentrations of free histamine (i.e., unbounded histamine) were determined by the HPLC method.

The adsorption capacity $(Q)$ was calculated by the following formula:

$$
Q=\left(C_{\mathrm{i}}-C_{\mathrm{e}}\right) \times \frac{V}{W}
$$

where $C_{\mathrm{i}}$ and $C_{\mathrm{e}}$ represent the initial and final concentration of histamine, respectively; $V$ is the volume of solution and $W$ represents the mass of polymer.

In addition, the Scatchard model, Freundlich model and Langmuir isotherm model were used to determine the affinity of UCNPs@MIPs-AgNPs and UCNPs@NIPs-AgNPs in the study. These three models were developed according to the equations as follows:

Scatchard model:

$$
\frac{Q}{C_{\mathrm{e}}}=\frac{Q_{\max }}{k_{\mathrm{d}}}-\frac{Q}{k_{\mathrm{d}}}
$$

Freundlich model:

$$
\lg Q=m \lg C_{e}+\lg a
$$

Langmuir isotherm model:

$$
\frac{C_{\mathrm{e}}}{Q}=\frac{C_{\mathrm{e}}}{Q_{\max }}+\frac{1}{Q_{\max } b}
$$

where $C_{\mathrm{e}}\left(\mathrm{mg} \mathrm{L}^{-1}\right)$ is the free histamine concentration $\left(\mathrm{mg} \mathrm{L}^{-1}\right)$ at equilibrium, $Q_{\max }$ is the saturated adsorption capacity $\left(\mathrm{mg} \mathrm{g}^{-1}\right), k_{\mathrm{d}}$ is the dissociation constant $\left(\mathrm{mg} \mathrm{\textrm {L } ^ { - 1 }}\right), m$ is the adsorption intensity of surface heterogeneity, a is the adsorption capacity of histamine $\left(\mathrm{mg} \mathrm{g}^{-1}\right)$ and $b$ is the Langmuir adsorption equilibrium constant $\left(\mathrm{L} \mathrm{mg}^{-1}\right)$.

For the study of kinetic adsorption of UCNPs@MIPs-AgNPs (or UCNPs@NIPs-AgNPs) towards histamine, a set of seven samples was incubated at $25{ }^{\circ} \mathrm{C}$ for different time points $(5,15$, 30, 45, 60, 90 and $150 \mathrm{~min}$ ). The mixture was treated and determined following the same procedures above mentioned for static adsorption.

The pseudo-first-order kinetic model and pseudo-secondorder kinetic model was used to describe the dynamic adsorption process according to eqn (5) and (6), respectively. ${ }^{34}$

$$
\begin{gathered}
\ln \left(Q-Q_{\mathrm{t}}\right)=\ln Q-k_{1} t \\
\frac{t}{Q_{\mathrm{t}}}=\frac{1}{k_{2} Q^{2}}+\frac{t}{Q}
\end{gathered}
$$

where $Q_{\mathrm{t}}$ represents the adsorption capacity $\left(\mathrm{mg} \mathrm{g}^{-1}\right)$ at a particular time point; $k_{1}$ means the rate constant of first-order sorption $\left(\ln \left(\mathrm{mg} \mathrm{g}^{-1} \mathrm{~s}^{-1}\right)\right) ; k_{2}$ is the rate constant of second-order sorption $\left(\mathrm{mg} \mathrm{g}^{-1} \mathrm{~s}^{-1}\right)$.

To evaluate the nature of diffusion process for histamine adsorption, the intra-particle diffusion model was introduced. The intra-particle mass transfer diffusion model proposed by Weber and Morris can be expressed as follows:

$$
Q_{\mathrm{t}}=k_{3} t^{1 / 2}+C
$$

where $C$ is the intercept $\left(\mathrm{mg} \mathrm{g}^{-1}\right)$ and $k_{3}$ is the intra-particle diffusion rate constant $\left(\mathrm{mg} \mathrm{g}^{-1} \mathrm{~s}^{-1 / 2}\right)$, which can be obtained from the slope of the linear plots of $Q_{\mathrm{t}} v s . t^{1 / 2}$.

The selectivity test was performed by comparing the adsorption capacity of UCNPs@MIPs-AgNPs (or UCNPs@NIPsAgNPs) towards histamine and that of its analogues at $75 \mathrm{mg} \mathrm{L}^{-1}$ after $45 \mathrm{~min}$ incubation. Herein, histamine, $\beta$-phenylethylamine, putrescine, spermine, spermidine, tryptamine, tyramine and cadaverine were selected as competitive agents to determine histamine selectivity of the UCNPs@MIPs-AgNPs.

The distribution coefficient $\left(K_{\mathrm{d}}\right)$, selectivity coefficient $(k)$ and the relative selectivity coefficient $(\alpha)$ of the sorbent obtained in these comparative experiments were also used to evaluate the competitive selective capacity of UCNPs@MIPs-AgNPs and UCNPs@NIPs-AgNPs. These three parameters were calculated following the equations below:

$$
K_{\mathrm{d}}=\frac{Q_{\mathrm{e}}}{C_{\mathrm{e}}}
$$

$$
k=\frac{K_{\mathrm{d}}(\text { histamine })}{K_{\mathrm{d}}(\text { analogues })}
$$

$$
\alpha=\frac{k_{\mathrm{MIP}}}{k_{\mathrm{NIP}}}
$$

$K_{\mathrm{d}}$ indicates the affinity of the sorbent for a particular substance. Generally, the larger the value of $K_{\mathrm{d}}$ is, the stronger the adsorption capability of a substance would be. The value of $k$ suggests the selectivity between the target analyte and its structural similar compounds. The value of $\alpha$ reveals how selective a sorbent is for a particular substance compared with the selectivity of a different sorbent.

\subsection{Fluorescence and SERS measurements}

Sample solutions containing various concentrations $\left(0.00 \mathrm{mg} \mathrm{L}^{-1}\right.$, $0.02 \mathrm{mg} \mathrm{L}{ }^{-1}, 0.1 \mathrm{mg} \mathrm{L}^{-1}, 1 \mathrm{mg} \mathrm{L}^{-1}, 5 \mathrm{mg} \mathrm{L}^{-1}, 10 \mathrm{mg} \mathrm{L}^{-1}$, 
$50 \mathrm{mg} \mathrm{L}^{-1}, 100 \mathrm{mg} \mathrm{L}^{-1}$ and $250 \mathrm{mg} \mathrm{L}^{-1}$ ) of histamine standard were mixed with $10 \mathrm{mg}$ of UCNPs@MIPs-AgNPs (UCNPs@NIPs-AgNPs). After shaking at room temperature for $45 \mathrm{~min}$, the fluorescence signal of the solution was scanned by using a Hitachi F-7000 fluorescence spectrometer equipped with an external $980 \mathrm{~nm}$ laser. For the blank $\left(0.00 \mathrm{mg} \mathrm{L}^{-1}\right)$, twenty measurements were performed. For other levels $\left(0.02 \mathrm{mg} \mathrm{L}^{-1}\right.$, $0.1 \mathrm{mg} \mathrm{L}^{-1}, 1 \mathrm{mg} \mathrm{L}^{-1}, 5 \mathrm{mg} \mathrm{L}{ }^{-1}, 10 \mathrm{mg} \mathrm{L}^{-1}, 50 \mathrm{mg} \mathrm{L}^{-1}$, $100 \mathrm{mg} \mathrm{L}^{-1}$ and $250 \mathrm{mg} \mathrm{L}^{-1}$ ), five measurements were performed.

For SERS detection, sample solutions containing various concentrations $\left(0.00 \mathrm{mg} \mathrm{L}^{-1}, 0.1 \mathrm{mg} \mathrm{L}^{-1}, 1 \mathrm{mg} \mathrm{L}^{-1}, 5 \mathrm{mg} \mathrm{L}^{-1}\right.$, $10 \mathrm{mg} \mathrm{L}^{-1}, 50 \mathrm{mg} \mathrm{L}^{-1}$ and $100 \mathrm{mg} \mathrm{L}^{-1}$ ) of histamine standard were mixed with $10 \mathrm{mg}$ of UCNPs@MIPs-AgNPs (UCNPs@ NIPs-AgNPs). After shaking at room temperature for $45 \mathrm{~min}$, the mixture then centrifuged at $5000 \times g$ for $5 \mathrm{~min}$. The supernatant was discarded and the pellet was dried before depositing onto the gold-coated microarray chip for SERS spectra collection. The SERS spectra were obtained by averaging the spectra detected at seven random different detection spots.

\subsection{Characterization}

The surface groups of the synthesized UCNPs and UCNPs@MIPs-AgNPs were measured using a FT-IR spectrophotometer (Nexus 670, Thermo Electron Corp., Madison, WI, USA) in the range of $650-4000 \mathrm{~cm}^{-1}$ with 256 scans at a resolution of $4 \mathrm{~cm}^{-1}$. The sample powders $(5 \mathrm{mg})$ were ground with spectroscopic grade $\mathrm{KBr}$ powders $(250 \mathrm{mg}$ ) and then pressed into $1 \mathrm{~mm}$ pellets. ${ }^{35}$ Morphologies of the synthesized nanoparticles were recorded by a high-resolution FEI Tecnai G2 20 transmission electron microscope equipped with a charge-coupled device (CCD) camera operating at an acceleration voltage of $200 \mathrm{kV}$. UV-vis absorption spectra were collected with a JASCO V570 UV/visible/NIR spectrophotometer (JASCO, Inc., Easton, MD, USA). A Bruker Senterra confocal Raman system (Billerica, MA, USA) coupled with $50 \times$ air objective (NA0.9, infinity and flat field corrected), a motorized microscope and a CCD array detector was employed for SERS spectra acquisition. The excited laser source was provided by a $785 \mathrm{~nm}$ air-cooled He-Ne laser at $10 \mathrm{~mW}$ and the exposure time for each SERS measurement was set at $10 \mathrm{~s}$. The spot diameter of laser source with our condition is about $12 \mu \mathrm{m}$. Upconversion fluorescence spectra were recorded on a Hitachi F-7000 fluorescence spectrophotometer (Hitachi Co., Tokyo, Japan) modified with an external 0-1300 $\mathrm{mW}$ adjustable continuous wave $980 \mathrm{~nm}$ laser (Beijing Hi-Tech Optoelectronic Co., Beijing, China) instead of the internal excitation source.

\subsection{Statistical analysis}

All data were expressed as mean \pm standard deviation (SD) of at least three determinations throughout the study, and spectra drawings were performed using Origin 8.5 (OriginLab Inc., Northampton, MA, USA). Data was analyzed using one-way analysis of variance and means were compared by Duncan's multiple range tests using SPSS 18.0 (SPSS Inc., Chicago, IL, USA). The probability value of $p<0.05$ was considered significant. The OMNIC software (v. 8.0, Thermo Electron Corp., Madison, WI, USA), OPUS 6.5 software (Opus Software, Inc., San Francisco, CA, USA) and FL Solutions 2.1 software (Hitachi High-technology Co., Tokyo, Japan) were utilized for FT-IR, Raman and fluorescence spectra acquisition and instrument control, respectively. Principal component analysis (PCA) was implemented in the commercial chemometric software The Unscrambler (v 10.2; CAMO Software AS, Oslo, Norway).

\section{Results and discussions}

\subsection{Analytical principle}

The typical dual-mode system for the detection of histamine based on fluorescence and SERS is illustrated in Scheme 1. The UCNPs@MIPs-AgNPs synthesized combined MIPs with fluorescence and SERS detection modalities. When histamine molecules were bound to the material, strong fluorescence quenching and prominent electromagnetic enhancement effect could occur simultaneously. The fluorescence quenching mechanism might not be through fluorescence resonance energy transfer since no overlap existed between the histamine absorption peak (at $\sim 210 \mathrm{~nm}$ ) and the UCNPs emission peak (at $541 \mathrm{~nm}$ ). The quenching mechanism could be attributed to the photo-induced electron transfer from histamine to UCNPs. The amine groups of histamine interacted with carboxyl groups in UCNPs@MIPs-AgNPs. The lone pair of electrons in oxygencontaining groups was available for photo-induced electron transfer, leading to a decrease in emission. When analytes were absorbed on the shell of MIPs, they (histamine molecules) also located closely to SERS-active substrates (AgNPs), which were incorporated in the outer shell of MIPs during polymerization, resulting in improved reproducibility of the SERS spectra. The methodology was proposed by Liu et al. ${ }^{36}$ They integrated AgNPs with MIPs by adding silver nitrate as AgNPs precursor that bind to theophylline during bulk polymerization. $\mathrm{Hu}$ et $\mathrm{al}^{37}$ successfully applied this methodology for the detection of melamine by integrating AgNPs with MIPs for melamine. Considering the fact that similar to the structure of theophylline, histamine also contains an imidazole ring, which could interact with AgNPs precursor during polymerization, this methodology was adopted in this study.

\subsection{Characterization of UCNPs@MIPs-AgNPs and UCNPs@NIPs-AgNPs}

3.2.1. TEM. The morphologies of UCNPs and UCNPs@MIPs-AgNPs were characterized by TEM. As shown in Fig. 1a, the synthesized UCNPs were spherical in shape with fairly uniform size of approximately $100 \mathrm{~nm}$, which was in accordance with the result reported by other researchers. ${ }^{33}$ Fig. 1c showed the TEM image of UCNPs@MIPs-AgNPs, and it could be clearly observed that there was a shell dotted with small nanoparticles (AgNPs) uniformly coated on the surface of the UCNPs, indicating that core-shell UCNPs (UCNPs@MIPs-AgNPs) were obtained.

3.2.2. FT-IR spectra. The FT-IR spectra of the synthesized UCNPs and UCNPs@MIPs-AgNPs were shown in Fig. 1b. For 


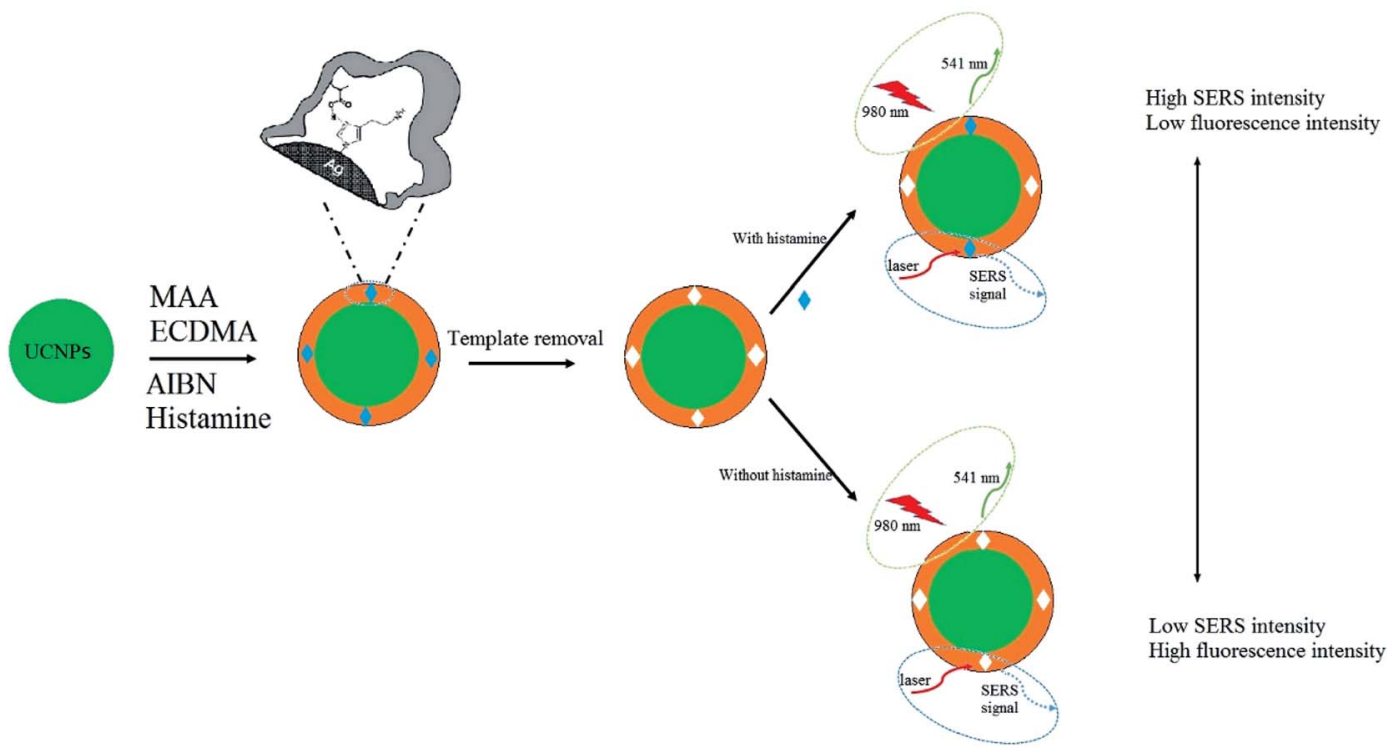

Scheme 1 Schematic illustration of the dual-mode assay for the detection of histamine.

the FT-IR spectrum of UCNPs, the dominating absorption peaks observed at around $2951 \mathrm{~cm}^{-1}$ and $2853 \mathrm{~cm}^{-1}$, corresponding to the bending vibrations of methylene $\left(-\mathrm{CH}_{2}-\right)$ and methyl groups $\left(\mathrm{CH}_{3}{ }^{-}\right)$respectively, and $1725 \mathrm{~cm}^{-1}$, which could be attributed to the stretching vibrations of the carbonyl group $(\mathrm{C}=\mathrm{O})$. After coating MIPs on the UCNPs, due to the existence of crosslinkers and monomers used to synthesize MIPs, the peak intensities at $2951 \mathrm{~cm}^{-1}, 2853 \mathrm{~cm}^{-1}$ and $1725 \mathrm{~cm}^{-1}$ were obviously enhanced. At the same time, a new peak at around $1170 \mathrm{~cm}^{-1}$ were observed in the spectrum of UCNPs@MIPsAgNPs. This band was assigned to the stretching vibration adsorption of ether group $(\mathrm{C}-\mathrm{O}-\mathrm{C}) \cdot{ }^{38}$ In addition, the peaks in the absorption band between $3200 \mathrm{~cm}^{-1}$ and $3800 \mathrm{~cm}^{-1}$ shifted from $3458 \mathrm{~cm}^{-1}$ in the spectrum of UCNPs to $3441 \mathrm{~cm}^{-1}$ in the spectrum for UCNPs@MIPs-AgNPs, which might be due to the interactions between the $-\mathrm{NH}_{2}$ group of the template molecule and the $\mathrm{C}=\mathrm{O}$ group of MAA. The spectra for UCNPs and UCNPs@MIPs-AgNPs had similar profiles (similar locations and appearances of the major bonds) indicated that they had same chemical nature. These results demonstrated that the polymerization on the surface of UCNPs particles had been successfully implemented.

3.2.3. Adsorption properties of UCNPs@MIPs-AgNPs and UCNPs@NIPs-AgNPs

3.2.3.1. Adsorption kinetics. To evaluate the selective recognition, binding capacity and equilibrium rate of the synthesized UCNPs@MIPs-AgNPs, static and kinetic adsorption tests were performed for both of UCNPs@MIPs-AgNPs and UCNPs@ NIPs-AgNPs. The kinetic adsorption curves were shown in Fig. 2a. Here, both the absorption capacities of UCNPs@MIPsAgNPs and UCNPs@NIPs-AgNPs increased with incubation time, reaching an adsorption equilibrium at around $45 \mathrm{~min}$. Thus, 45 min was chosen as optimal extraction time. Note that at all conditions, the amount of histamine binding to UCNPs@MIPs-AgNPs was remarkably higher than that of
UCNPs@NIPs-AgNPs, verifying the superior performance of UCNPs@MIPs-AgNPs versus UCNPs@NIPs-AgNPs with respect to histamine binding. The binding capacity of UCNPs@NIPsAgNPs was contributed by nonspecific binding, which was hypothesized to be driven by the interruption of the hydrogenbond interactions by the solvent media. UCNPs@MIPs-AgNPs contained of nonspecific binding sites as well as specific reorganization sites, which was ascribed to the host-guest shape and size recognition and the bond reaction between them. However, the number of non-specific binding sites was limited. That explained why much higher $Q$ value for UCNPs@MIPsAgNPs was observed compared with that of UCNPs@NIPsAgNPs.

Three different models, namely pseudo-first-order kinetic model, pseudo-second-order kinetic model and intra-particle diffusion model, were chosen to investigate dynamic adsorption mechanism of histamine. As seen in Fig. $2 \mathrm{~b}$ and 3, the adsorption reaction of UCNPs@MIPs-AgNPs towards histamine could be well fitted by both of pseudo-first-order kinetic model and pseudo-second-order kinetic model while the fitting performance of intra-particle diffusion model was far worse. In addition, compared with pseudo-first-order kinetic model and intra-particle diffusion model, the pseudo-second-order kinetic model described the adsorption behavior of UCNPs@MIPsAgNPs on histamine with higher $R^{2}$ (0.9965). Moreover, the theoretical $Q_{\mathrm{e}}$ value calculated from the slope of the pseudosecond-order kinetic model $\left(t / Q_{\mathrm{t}}\right.$ versus $\left.t\right)$ was $1.85 \mathrm{mg} \mathrm{g}^{-1}$, closed to the $Q_{\mathrm{e}}$ value $\left(1.80 \mathrm{mg} \mathrm{g}^{-1}\right)$ obtained from the experiment. These results indicated that instead of intra-particle diffusion, the adsorption process of UCNPs@MIPs-AgNPs towards histamine was controlled by chemical adsorption mechanism by sharing electrons between them. ${ }^{39}$

3.2.3.2. Static binding characteristics. The static adsorption capacities of UCNPs@MIPs-AgNPs and UCNPs@NIPs-AgNPs for histamine were determined in the concentration range from 


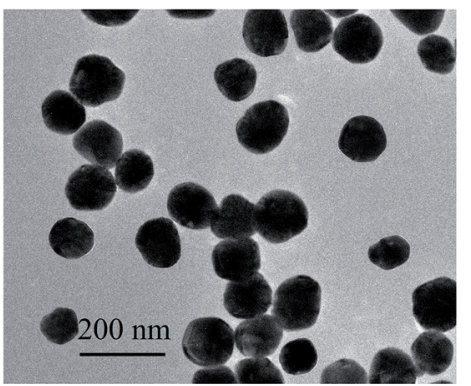

b

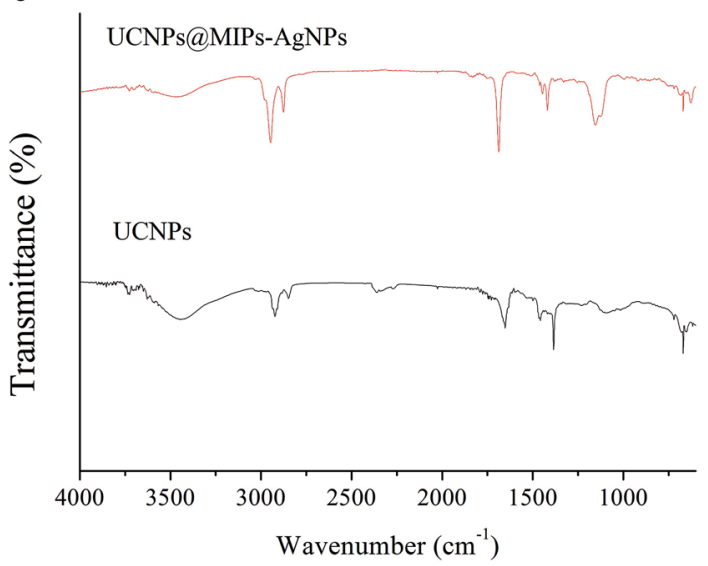

$\mathrm{C}$

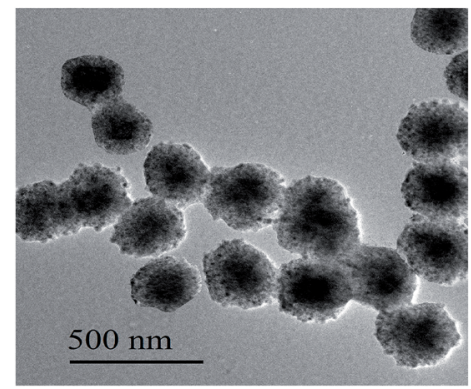

Fig. 1 (a) TEM image of UCNPs; (b) FT-IR spectra of UCNPs and UCNPs@MIPs-AgNPs; (c) TEM image of UCNPs@MIPs-AgNPs.
$10 \mathrm{mg} \mathrm{L}^{-1}$ to $200 \mathrm{mg} \mathrm{L}^{-1}$, and the relationship of their total adsorption capacities to the concentration of histamine was presented in Fig. 4a.

It can be seen from the static adsorption isotherm curves that the adsorption capacities for both UCNPs@MIPs-AgNPs and UCNPs@NIPs-AgNPs increased along with the increase in the initial concentration of histamine. In addition, the adsorption capacities of UCNPs@MIPs-AgNPs were constantly higher than those of UCNPs@NIPs-AgNPs, which was similar to the results of kinetic adsorption experiments. Specifically, when

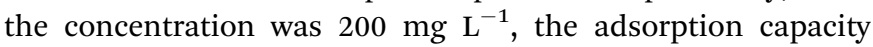
of MIPs (3.11 $\mathrm{mg} \mathrm{g}^{-1}$ ) was about 4.5 times that of NIPs (0.70 $\left.\mathrm{mg} \mathrm{g}^{-1}\right)$, illustrating that the chemical and physical properties of histamine had been successfully imprinted into UCNPs@MIPs-AgNPs. As a result, UCNPs@MIPs-AgNPs have higher specific recognition ability toward histamine than UCNPs@NIPs-AgNPs and were suitable for further application. Generally, increasing the polarity of the solution reduces the adsorption capacity in both cases.

Scatchard relationship was determined to assess the affinity of UCNPs@MIPs-AgNPs toward histamine. As shown in Fig. 4b, two intersecting straight lines with different slopes corresponding to the high- and low-affinity populations of binding sites were observed in the Scatchard plot. By contrast, UCNPs@NIPs-AgNPs showed nonlinearity, indicating that there was no selective adsorption sites for histamine. To further estimate the binding properties of UCNPs@MIPs-AgNPs, the isotherm absorption data were also processed with the Freundlich and Langmuir adsorption isotherm models and shown in Fig. $5 \mathrm{a}$ and $\mathrm{b}$. The results demonstrated that the binding process of histamine with the UCNPs@MIPs-AgNPs could be well fitted by the two isotherm models $\left(R^{2}=0.9994\right.$ and 0.9754 for Freundlich model and Langmuir model, respectively), indicating that UCNPs@MIPs-AgNPs possessed a heterogeneous binding site distribution.

3.2.3.3. Adsorption selectivity. To evaluate the specificity of the UCNPs@MIPs-AgNPs, several analogues of structural features of histamine were selected, including $\beta$-phenylethylamine, putrescine, spermidine, spermine, tryptamine, tyramine

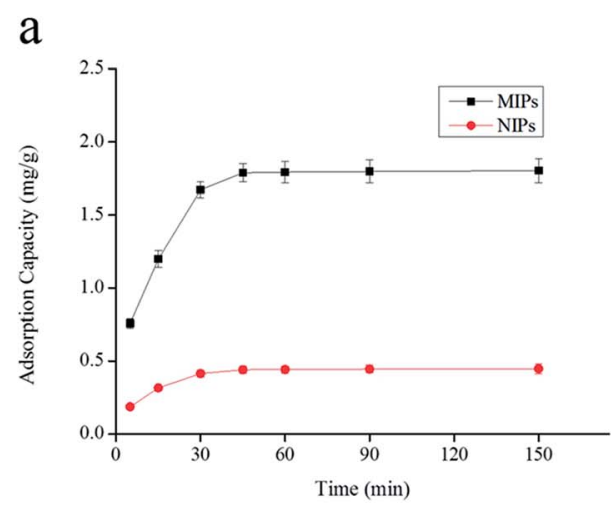

b

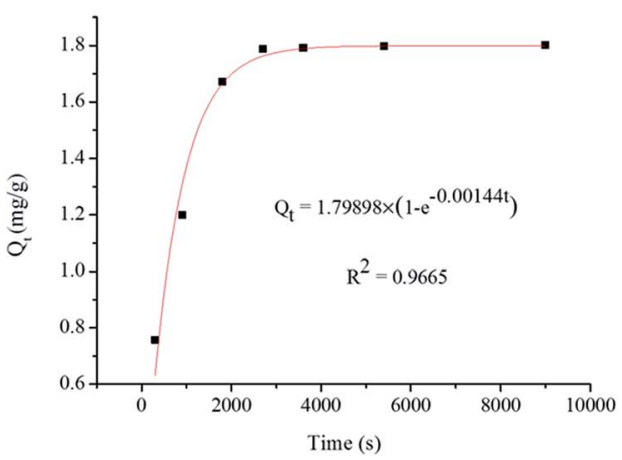

Fig. 2 Characterization of the kinetic adsorption properties of UCNPs@MIPs-AgNPs and UCNPs@NIPs-AgNPs (initial histamine concentration: $C_{i}=75 \mathrm{mg} \mathrm{L}^{-1}$ ). (a) Uptake kinetics study of UCNPs(MMIPs-AgNPs and UCNPs(NIPs-AgNPs; (b) pseudo-first-order kinetic model for the adsorption of histamine by UCNPs@MIPs-AgNPs. 
a

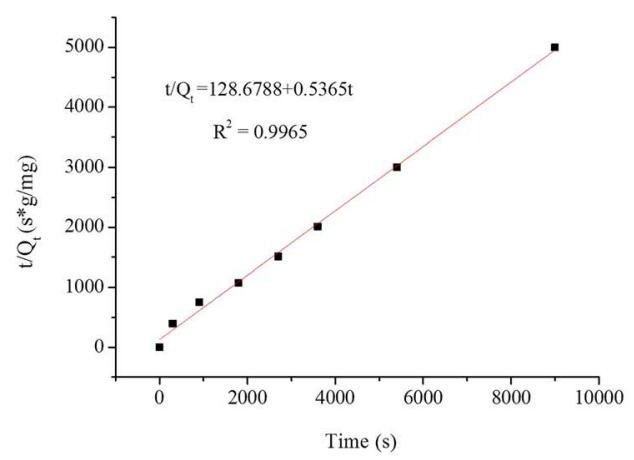

b

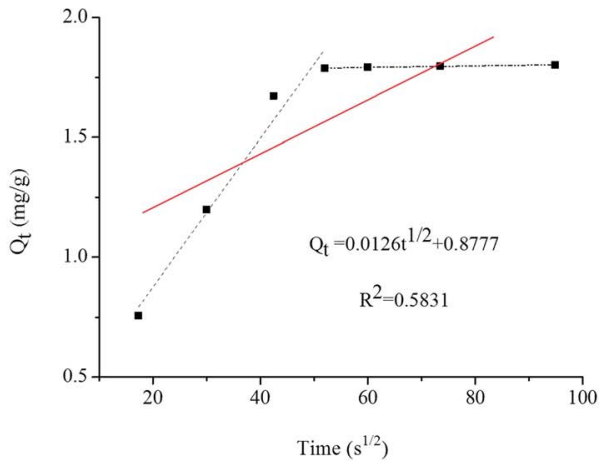

Fig. 3 (a) Pseudo-second-order kinetic model for the adsorption of histamine by UCNPs@MIPs-AgNPs; (b) intra-particle diffusion model for the adsorption of histamine by UCNPs(MIPs-AgNPs.

a

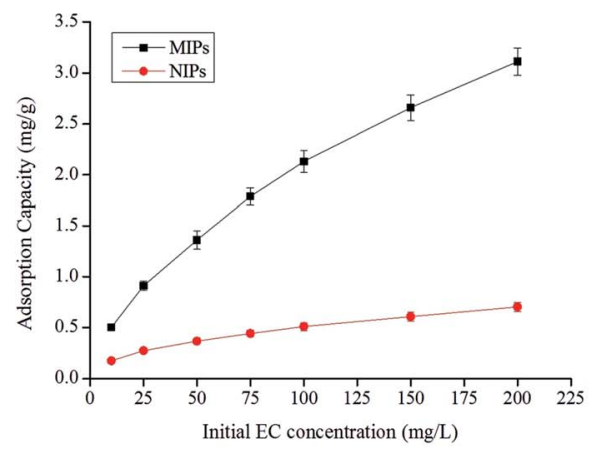

b

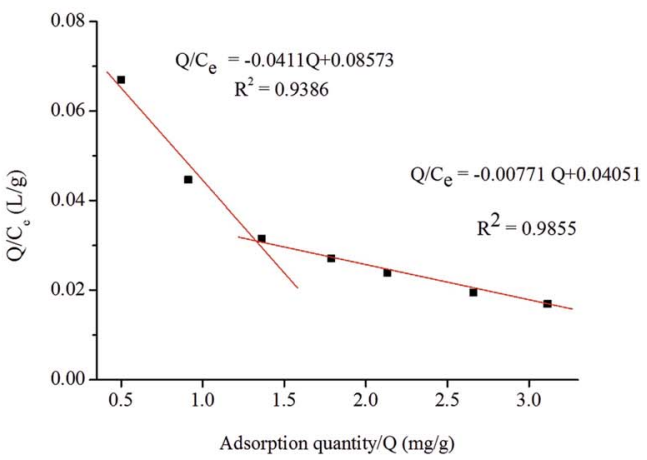

Fig. 4 Characterization of the static adsorption properties of UCNPs@MIPs-AgNPs and UCNPs@NIPs-AgNPs. (a) Adsorption isotherm curves of binding isotherms of UCNPs@MIPs-AgNPs and UCNPs@NIPs-AgNPs; (b) Scatchard plot of UCNPs@MIPs-AgNPs toward histamine.

and cadaverine. The competitive adsorption experiments of these analogues with histamine on the sorbents were carried out with $75 \mathrm{mg} \mathrm{L}^{-1}$ of standard solution. The molecular structures of the analytes and binding amounts of these targets on UCNPs@MIPs-AgNPs and UCNPs@NIPs-AgNPs were shown in Fig. 6. As seen from the figure, histamine owned remarkably higher binding capacity than its analogues, suggesting satisfactory selectivity of the synthesized UCNPs@MIPs-AgNPs for histamine. Table 1 and Table 2 summarized the values of $K_{\mathrm{d}}, k$ and $\alpha$, which were calculated to evaluate the competitive selective capabilities of UCNPs@MIPs-AgNPs and UCNPs@ NIPs-AgNPs. As shown in Table 1 , the $K_{\mathrm{d}}$ of histamine was
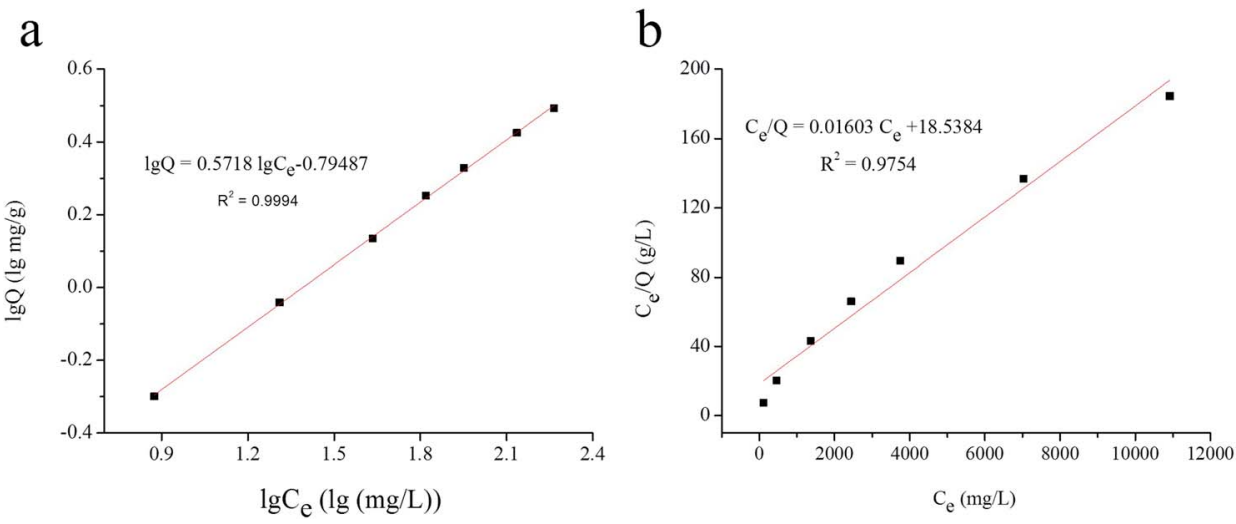

Fig. 5 (a) Adsorption isotherms of Freundlich model for UCNPs@MIPs-AgNPs toward histamine; (b) adsorption isotherms of Langmuir model for UCNPs@MIPs-AgNPs toward histamine. 
a

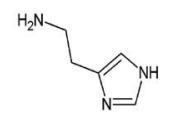<smiles>NCCCCN</smiles>

Histamine<smiles>NCCCNCCCCNCCCN</smiles><smiles>NCCCCNCCCCN</smiles>

Spermidine<smiles>NCCc1ccccc1</smiles>

$\beta$-phenylethylamine

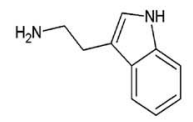

Tryptamine<smiles>NCCc1ccc(O)cc1</smiles>

Tyramine b

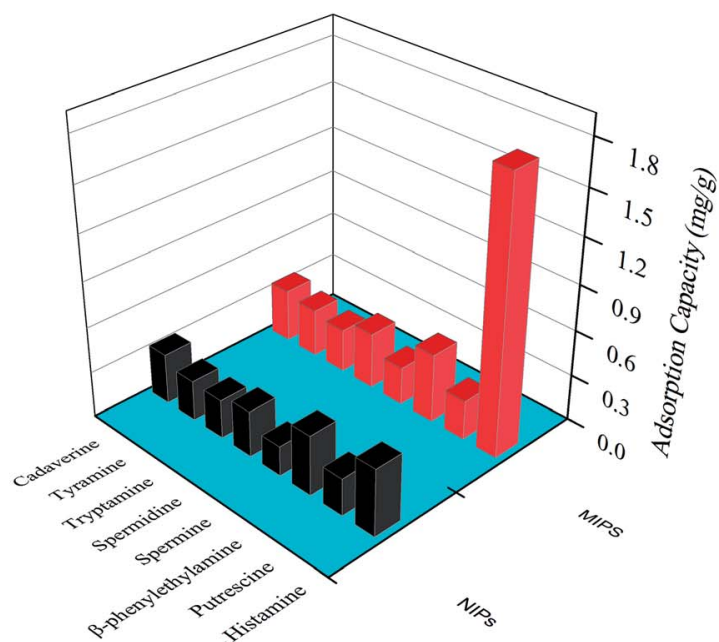

Fig. 6 (a) Chemical structures and of histamine and its structural analogues; (b) selective recognition of UCNPs@MIPs-AgNPs and UCNPs@NIPs-AgNPs for histamine and its structural analogues.

Table 1 Parameter $\left(K_{\mathrm{d}}\right)$ used to evaluate selectivity of UCNPs@MIPs-AgNPs and UCNPs@NIPs-AgNPs towards histamine

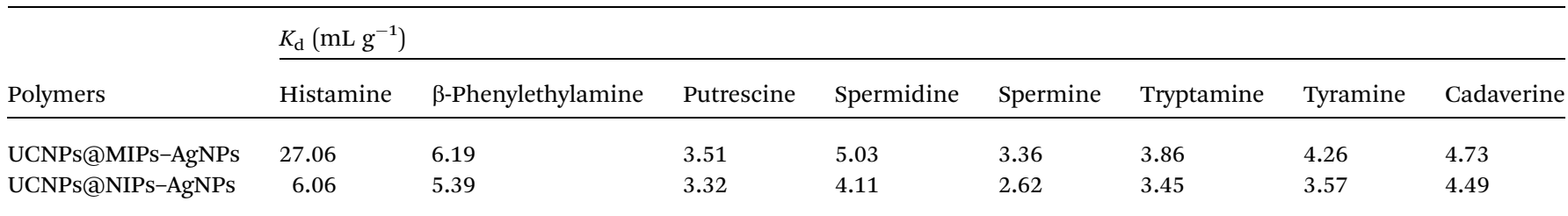

Table 2 Parameters $(k$ and $\alpha$ ) used to evaluate selectivity of UCNPs@MIPs-AgNPs and UCNPs@NIPs-AgNPs towards histamine

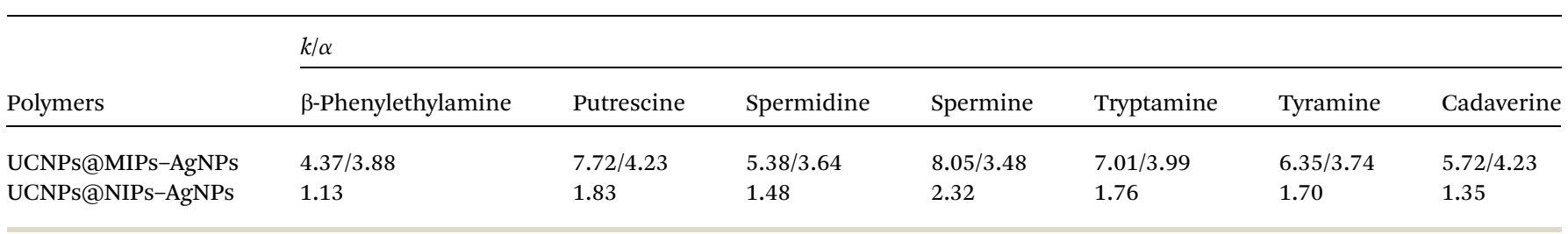

clearly larger than that of the other seven structure analogues of histamine, validating the strong adsorption capacity of UCNPs@NIPs-AgNPs for histamine. In addition, the $k$ value of seven structural analogues for UCNPs@MIPs-AgNPs was several times higher than the corresponding values for UCNPs@NIPs-AgNPs (Table 2), suggesting that the UCNPs@MIPs-AgNPs offering more specific recognition sites for the target molecule (i.e. histamine) than non-target substances. The relatively high $\alpha$ values (>1) of $\beta$-phenylethylamine, putrescine, spermidine, spermine, tryptamine, tyramine and cadaverine further confirmed that UCNPs@MIPs-AgNPs for histamine was successfully synthesized and the rebinding occurred specifically and selectively for histamine rather than its structural analogues.

\subsection{Analytical performance}

3.3.1. Detection of histamine using fluorescence mode. Fig. 7 showed various intensities of the fluorescence spectra of UCNPs@MIPs-AgNPs in the presence of different concentrations of histamine. In the fluorescence spectra, three dominant emission peaks were observed at 488, 541 and $665 \mathrm{~nm}$, which were mainly generated by the transitions from the ${ }^{2} \mathrm{H}_{9 / 2},{ }^{4} \mathrm{~S}_{3 / 2}$, and ${ }^{4} \mathrm{~F}_{9 / 2}$ levels to the ${ }^{4} \mathrm{I}_{15 / 2}$ ground state of the $\mathrm{Er}^{3+}$ ion. ${ }^{17}$

As seen in Fig. 7a, within the histamine concentration range of $0.02-250 \mathrm{mg} \mathrm{L}^{-1}$, the fluorescence intensities of UCNPs@MIPs-AgNPs gradually decreased as the concentration of the target (histamine) increased. Principal component analysis (PCA) was performed to further explain the fluorescence spectra. As shown in Fig. 8a, the explained variation rate for the first two principle components (PCs) was 64\% (PC1) and 18\% (PC2), respectively, which indicated that the first two PCs could fairly well represent the essential features of the fluorescence spectra. In addition, there was a clear separation tendency between samples containing different levels of histamine, suggesting samples containing different levels of histamine can be well discriminated using 

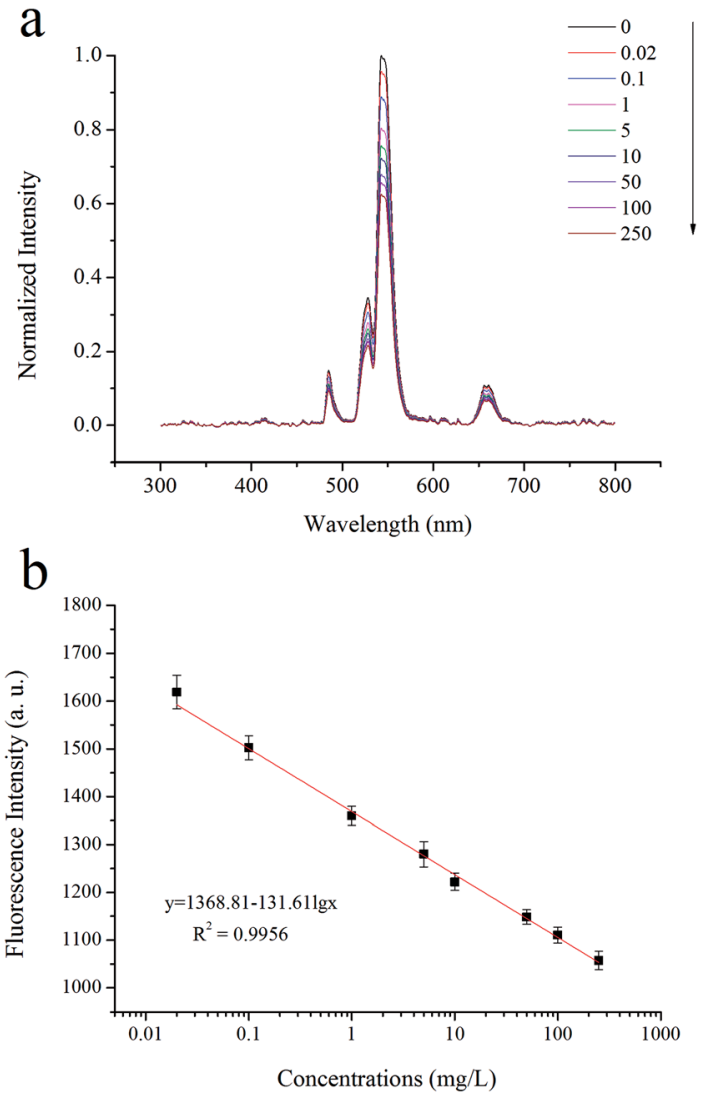

Fig. 7 (a) Fluorescence emission spectra of UCNPs@MIPs-AgNPs in different concentrations of histamine; (b) linear relationship between the upconversion fluorescence intensities and histamine concentrations in the range of $0.02-250 \mathrm{mg} \mathrm{L}^{-1}$.

fluorescence spectroscopy. There was a good linear relationship (correlation coefficient of 0.9956 for a linear regression fit, $y=1368.81-131.61 \lg x$ (Fig. 7b)) between the fluorescence intensities and the log plot for the concentrations of histamine in samples. Moreover, the detection limit (LOD) and quantitation limit (LOQ) of the sensing system were calculated to be $0.009 \mathrm{mg} \mathrm{L}^{-1}$ and $0.02 \mathrm{mg} \mathrm{L}^{-1}$, respectively.
3.3.2. Detection of histamine using SERS mode. Fig. 9 displayed spectral features of histamine determined by the normal Raman and SERS spectra while Fig. 10 demonstrated the linear correlation between the SERS intensities and the concentrations of histamine. As seen in Fig. 9, some band shifts existed, which might be due to the SERS effect. When target molecules adsorbed onto the surface of substrate, some molecules interacted with the noble-metallic nanostructures, resulting in the changes in dipole of the molecules and subsequent shifts in the location of SERS bands. ${ }^{13}$ Four major peaks at around $1268 \mathrm{~cm}^{-1}, 1331 \mathrm{~cm}^{-1}, 1427 \mathrm{~cm}^{-1}$ and $1572 \mathrm{~cm}^{-1}$ were observed in similar positions in both of normal Raman spectra of histamine powder and SERS spectra of histamine solution. These four strong peaks were also reported by Gao et $a .^{4}{ }^{4}$ and Janči et $a l^{40}$ The Raman peaks at $1268 \mathrm{~cm}^{-1}$, $1331 \mathrm{~cm}^{-1}$ and $1572 \mathrm{~cm}^{-1}$ might be related to the imidazole ring stretching and breathing while the peak at $1427 \mathrm{~cm}^{-1}$ was assigned to vibrations of carboxylic group. As shown in Fig. 10a, the changes of these four strong Raman peaks depend on histamine concentrations. The SERS intensities of UCNPs@MIPs-AgNPs increased as the concentration of histamine increased. A preliminary analysis of data was also performed by PCA to examine any possible grouping of samples according to

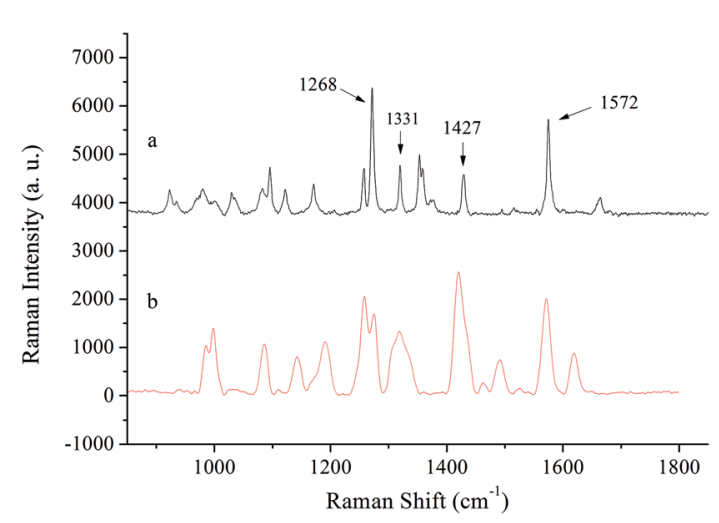

Fig. 9 Comparison of (a) normal Raman spectrum of histamine crystal powder and (b) SERS spectrum of histamine solution. a

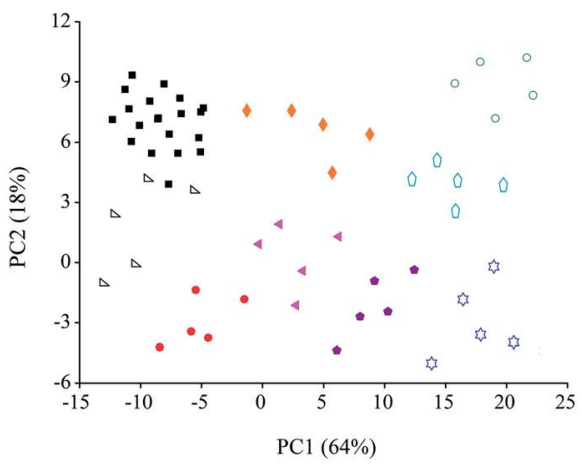

b

\begin{tabular}{|c|c|}
\hline & $0 \mathrm{mg} / \mathrm{L}$ \\
\hline$\triangle$ & $0.02 \mathrm{mg} / \mathrm{L}$ \\
\hline & $0.1 \mathrm{mg} / \mathrm{L}$ \\
\hline 4 & $1 \mathrm{mg} / \mathrm{L}$ \\
\hline . & $5 \mathrm{mg} / \mathrm{L}$ \\
\hline 0 & $10 \mathrm{mg} / \mathrm{L}$ \\
\hline & $50 \mathrm{mg} / \mathrm{L}$ \\
\hline s & $100 \mathrm{mg} / \mathrm{L}$ \\
\hline 0 & $250 \mathrm{mg} / \mathrm{L}$ \\
\hline
\end{tabular}

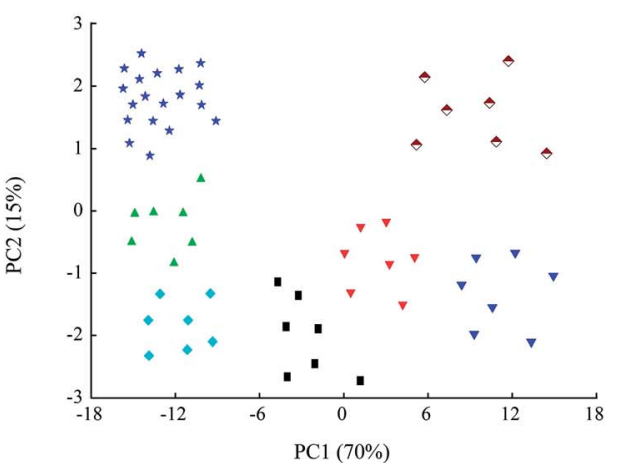

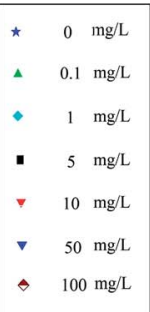

$100 \mathrm{mg} / \mathrm{L}$

Fig. 8 Principal component score plots of the samples with different concentrations of histamine under fluorescence mode (a) and SERS mode (b). 


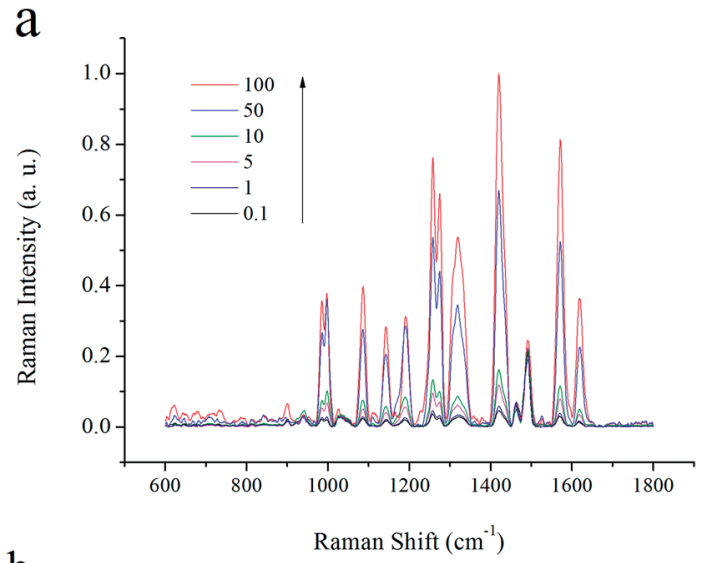

b

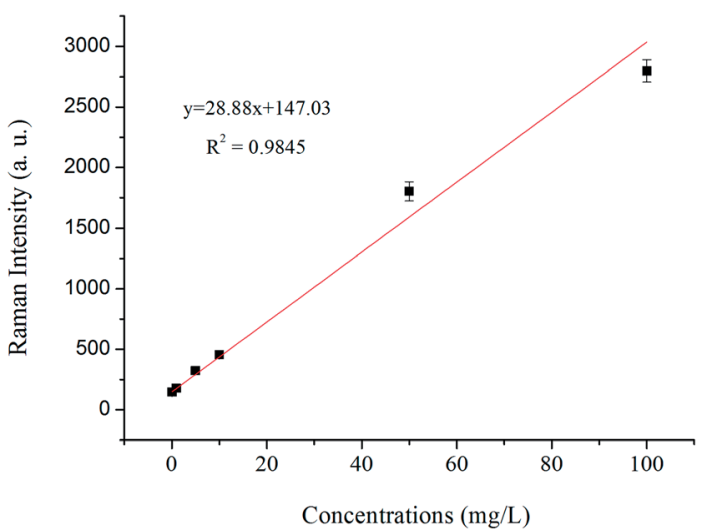

Fig. 10 (a) Typical SERS response of UCNPs(MIPs-AgNPs in various histamine concentrations; (b) linear correlation between the SERS Raman intensities and the concentrations of histamine.

the histamine contents in samples. The first two PCs explained $70 \%$ and $15 \%$ of the total variation, respectively, indicating that the cumulative reliabilities could explain most of the Raman spectra information so that they could be used to represent the variables for classification of samples. Fig. $8 \mathrm{~b}$ showed the score plots of the first and the second principle components, with samples shaped according to different histamine levels. A clear separation was also observed, suggesting samples containing different levels of histamine could also be well discriminated with Raman spectroscopy. Within the histamine concentration range of $0.1-100 \mathrm{mg} \mathrm{L}^{-1}$, highest intensity was observed at $1427 \mathrm{~cm}^{-1}$, followed by $1572 \mathrm{~cm}^{-1}, 1268 \mathrm{~cm}^{-1}$ and $1331 \mathrm{~cm}^{-1}$. The intensities of these four major peaks were selected for quantitative evaluation. Here, six critical levels $\left(0.1 \mathrm{mg} \mathrm{L}^{-1}\right.$, $1 \mathrm{mg} \mathrm{L}^{-1}, 5 \mathrm{mg} \mathrm{L}^{-1}, 10 \mathrm{mg} \mathrm{L}^{-1}, 50 \mathrm{mg} \mathrm{L}^{-1}$ and $100 \mathrm{mg} \mathrm{L}^{-1}$ ) were used to establish calibration curves. It appeared that the SERS intensities at $1331 \mathrm{~cm}^{-1}$ showed better does-dependence effect than the other three peaks. From this observation, peak intensities at $1331 \mathrm{~cm}^{-1}$ was adopted and used for further assessment. The correlation between the SERS Raman intensities and the concentrations of histamine based on peak intensities at $1331 \mathrm{~cm}^{-1}$ was shown in Fig. 10b. A good linear relationship between the SERS Raman intensities and the concentrations of histamine was obtained. The linear regression equation fit obtained was of $y=28.88 x+147.03$ with the correlation coefficient of 0.9845 . The LOD and LOQ value of the sensor system under SERS mode were $0.04 \mathrm{mg} \mathrm{L}^{-1}$ and $0.1 \mathrm{mg} \mathrm{L}^{-1}$ respectively.

For comparison, the analytical performances of some currently used detection methods for histamine reported in the literature are provided in Table 3. As seen from the results, the LOD obtained from the proposed method was significantly lower.

\subsection{Analytical application}

The accuracy of the proposed dual mode bioassay for determining histamine levels in real food samples was evaluated by detecting histamine in red wine, rice wine and canned tuna samples spiked with a series of known quantities of histamine $\left(5,15\right.$ and $\left.30 \mathrm{mg} \mathrm{L}^{-1}\right)$. The results of recoveries were summarized in Table 4. All of the three spiking levels in red wine, rice wine and canned tuna samples showed good recoveries. It was worth noting that the recovery results of canned tuna ranged from $85.06 \%$ to $117.36 \%$, which were not as good as the results from wine samples $(93.30-108.30 \%)$. This could be due to the fact that the matrix in canned tuna was more complex than that of red wine and rice wine samples. In addition, food samples spiked with histamine at three levels were analyzed by HPLC-UV

Table 3 Comparison of the results for histamine detection obtained from our method and that reported by others

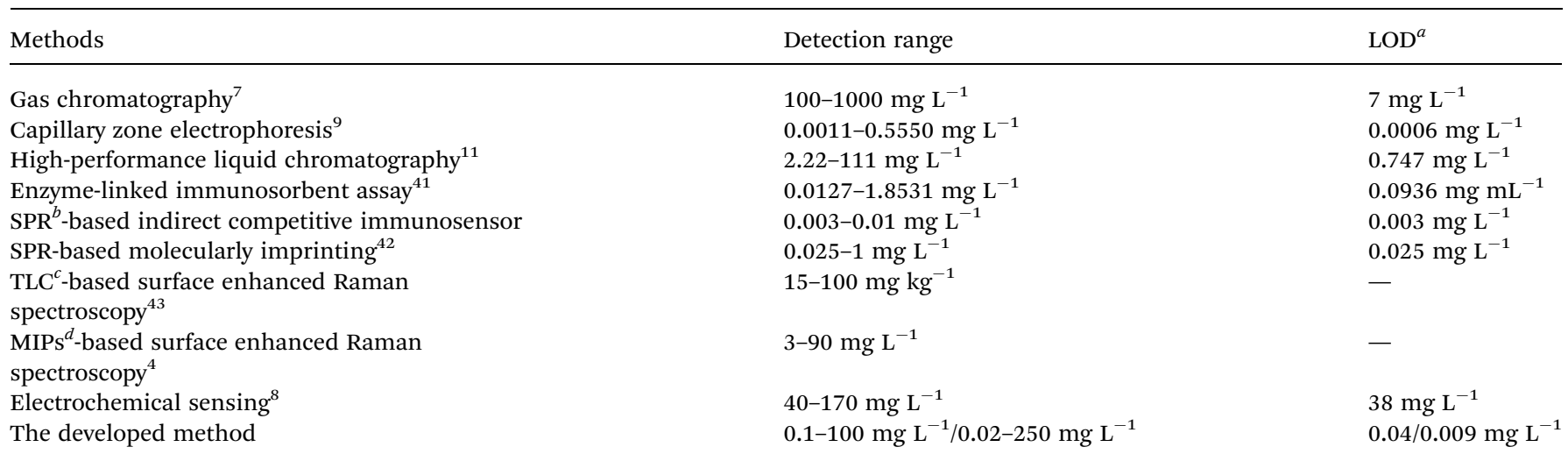

${ }^{a}$ Limit of detection. ${ }^{b}$ Surface plasmon resonance. ${ }^{c}$ Thin-layer chromatography. ${ }^{d}$ Molecularly imprinted polymers. 
Table 4 Detection and recovery results of histamine-spiked red wine, rice wine and canned tuna samples by HPLC and the proposed strategy

\begin{tabular}{|c|c|c|c|c|c|c|c|}
\hline \multirow[b]{3}{*}{ Sample } & \multirow[b]{3}{*}{$\begin{array}{l}\text { Background content } \\
\left(\mathrm{mg} \mathrm{kg}^{-1} \text { or } \mathrm{mg} \mathrm{L}^{-1}\right)\end{array}$} & \multirow[b]{3}{*}{$\begin{array}{l}\text { Spiked levels } \\
\left(\mathrm{mg} \mathrm{L}^{-1}\right)\end{array}$} & \multicolumn{5}{|c|}{ Detection results } \\
\hline & & & \multirow[b]{2}{*}{ HPLC-UV } & \multicolumn{4}{|c|}{ Detected by UCNPs@MIPs-AgNPs } \\
\hline & & & & $\begin{array}{l}\text { Fluorescence } \\
\text { mode }\end{array}$ & $\begin{array}{l}\text { Recovery } \\
\text { ratio (\%) }\end{array}$ & $\begin{array}{l}\text { SERS } \\
\text { mode }\end{array}$ & $\begin{array}{l}\text { Recovery } \\
\text { ratio (\%) }\end{array}$ \\
\hline \multirow[t]{6}{*}{ Red wine } & 0.34 & 5 & 5.48 & 5.78 & 108.30 & 5.46 & 102.23 \\
\hline & 0.34 & 15 & 15.66 & 16.12 & 105.09 & 15.13 & 98.64 \\
\hline & 0.34 & 30 & 30.15 & 32.50 & 107.12 & 30.26 & 99.72 \\
\hline & 2.58 & 5 & 7.15 & 7.19 & 94.88 & 7.38 & 97.33 \\
\hline & 2.58 & 15 & 18.05 & 17.26 & 98.17 & 17.86 & 101.61 \\
\hline & 2.58 & 30 & 32.89 & 31.80 & 97.60 & 31.21 & 95.81 \\
\hline \multirow[t]{6}{*}{ Rice wine } & 0.23 & 5 & 5.66 & 5.063 & 96.81 & 4.92 & 94.09 \\
\hline & 0.23 & 15 & 15.49 & 14.21 & 93.30 & 15.92 & 104.53 \\
\hline & 0.23 & 30 & 28.97 & 29.91 & 98.94 & 28.35 & 93.78 \\
\hline & 5.76 & 5 & 10.22 & 11.47 & 106.60 & 10.83 & 100.65 \\
\hline & 5.76 & 15 & 20.05 & 19.66 & 94.70 & 21.24 & 102.31 \\
\hline & 5.76 & 30 & 35.90 & 37.16 & 103.91 & 35.28 & 98.66 \\
\hline \multirow[t]{6}{*}{ Canned tuna } & 0.19 & 5 & 5.27 & 4.82 & 92.87 & 5.39 & 103.85 \\
\hline & 0.19 & 15 & 15.03 & 16.56 & 109.02 & 17.23 & 113.43 \\
\hline & 0.19 & 30 & 30.32 & 35.43 & 117.36 & 25.68 & 85.06 \\
\hline & 0.87 & 5 & 5.64 & 5.65 & 96.25 & 5.37 & 91.48 \\
\hline & 0.87 & 15 & 16.05 & 13.79 & 86.89 & 15.06 & 94.90 \\
\hline & 0.87 & 30 & 31.31 & 28.17 & 91.25 & 33.34 & 108.00 \\
\hline
\end{tabular}

to verify the practicability of the developed method. No significant difference $(p>0.05)$ in the results were observed from the proposed analysis and those obtained with HPLC-UV, indicating that the proposed method had great potential for histamine detection in red wine and rice wine samples.

Compared to the commonly used quantum dots (QDs) and organic dyes, UCNPs has lower autofluorescence background, better photochemical stability, larger Stokes shifts nonblinking property and lower toxicity. These outstanding photo-physical properties make it a potential candidate for further studies. In this study, by integrating fluorescence sensing and SERS, we have established a dual mode counterpropagating-responsive method for the detection of histamine. With this dual-mode system, positive SERS response and negative fluorescence response could be achieved simultaneously, which ensured more reliable and precise quantification of histamine compared with single fluorescence sensing or SERS-based method. We believe that our method shows excellent promise in the quantitation of harmful chemicals in food products.

\section{Conclusions}

A novel sensor combined the sensitivity of the upconverting and SERS technologies and the specificity of MIPs was developed. Excellent reorganization specificity, wide linear range and a low detection limit were achieved using this sensing system. In addition, the fabricated system was successfully applied to detect histamine in red wine, rice wine and canned tuna samples with good recovery. The novel strategy demonstrated great potential in sensitive and economic detection of histamine in wine samples required by both government laboratories and food industry. This easy-to-operate method could be extended to detect other hazardous substances in food samples.

\section{Conflicts of interest}

There are no conflicts of interest to declare.

\section{Acknowledgements}

This research was supported by funds from USDA-ARS (No. 1935-42000-049-00D) in conjunction with the Center for Food Safety Engineering at Purdue University, the Nature Science Foundation of Jiangsu Province (No. BK20160168), the National Key Technology R\&D Program for the 12th Five-Year Plan (No. 2016YFD0400304), the independent research project program of the State Key Laboratory of Food Science and Technology of Jiangnan University (No. JUSRP1029), the Nature Science Foundation of China (No. 31601413 and 31501418) and the graduate student innovation project of Jiangsu province (KYLX15_1134). The author Wu Zhengzong is thankful for the funding from Chinese Scholarship Council (CSC).

\section{References}

1 J. Collado, I. Tunon, E. Silla and F. Ramírez, J. Phys. Chem. A, 2000, 104, 2120-2131.

2 J. W. Black, W. A. M. Duncan, C. J. Durant, C. R. Ganellin and E. M. Parsons, Nature, 1972, 236, 385-390.

3 J. Dai, Y. Zhang, M. Pan, L. Kong and S. Wang, J. Agric. Food Chem., 2014, 62, 5269-5274.

4 F. Gao, E. Grant and X. Lu, Anal. Chim. Acta, 2015, 901, 68-75.

5 T. Janči, D. Valinger, J. Gajdoš Kljusurić, L. Mikac, S. Vidaček and M. Ivanda, Food Chem., 2017, 224, 48-54.

6 S. Phuvasate and Y.-C. Su, Food Control, 2010, 21, 286-291. 
7 F. R. Antoine, C.-i. Wei, W. S. Otwell, C. A. Sims, R. C. Littell, A. D. Hogle and M. R. Marshall, J. Agric. Food Chem., 2002, 50, 4754-4759.

8 J. A. Young, X. Jiang and J. R. Kirchhoff, Electroanalysis, 2013, 25, 1589-1593.

9 L.-Y. Zhang and M.-X. Sun, J. Chromatogr. A, 2004, 1040, 133140.

10 D. E. Schutz, G. W. Chang and L. F. Bjeldanes, J. - Assoc. Off. Anal. Chem., 1976, 59, 1224-1225.

11 J. Kirschbaum, I. Busch and H. Brückner, Chromatographia, 1997, 45, 263-268.

12 A. Marcobal, M. C. Polo, P. J. Martín-Álvarez and M. V. Moreno-Arribas, Food Res. Int., 2005, 38, 387-394.

13 Z. Wu, E. Xu, J. Li, J. Long, A. Jiao and Z. Jin, RSC Adv., 2016, 6, 109442-109452.

14 D. Cozzolino, Appl. Spectrosc. Rev., 2016, 51, 302-317.

15 P. Meksiarun, M. Ishigaki, V. A. Huck-Pezzei, C. W. Huck, K. Wongravee, H. Sato and Y. Ozaki, Sci. Rep., 2017, 7, 44890.

16 B. Zhang, H. Tao, X. Niu, S. Li and H.-Q. Chen, Food Chem., 2017, 227, 137-141.

17 Z. Wu, E. Xu, M. F. J. Chughtai, Z. Jin and J. Irudayaraj, Food Chem., 2017, 230, 673-680.

18 R. Hao, C. Ye, X. Wang, L. Zhu, S. Chen, J. Yang and X.-T. Tao, J. Phys. Chem. C, 2017, 121, 13524-13531.

19 D. Mendez-Gonzalez, M. Laurenti, A. Latorre, A. Somoza, A. Vazquez, A. I. Negredo, E. López-Cabarcos, O. G. Calderón, S. Melle and J. Rubio-Retama, ACS Appl. Mater. Interfaces, 2017, 9, 12272-12281.

20 X. Liu, L. Su, L. Zhu, X. Gao, Y. Wang, F. Bai, Y. Tang and J. Li, Sens. Actuators, B, 2016, 233, 394-401.

21 P. Vilela, A. El-Sagheer, T. M. Millar, T. Brown, O. L. Muskens and A. G. Kanaras, ACS Sens., 2016, 2, 52-56.

22 C. Drees, A. N. Raj, R. Kurre, K. B. Busch, M. Haase and J. Piehler, Angew. Chem., Int. Ed., 2016, 55, 11668-11672.

23 Y. Wang, K. Lee and J. Irudayaraj, Chem. Commun., 2010, 46, 613-615.

24 Y. Wang and J. Irudayaraj, Philos. Trans. R. Soc., B, 2013, 368, 20120026.
25 B. Ankamwar, U. K. Sur and P. Das, Anal. Methods, 2016, 8, 2335-2340.

26 Y. Wang, K. Lee and J. Irudayaraj, J. Phys. Chem. C, 2010, 114, 16122-16128.

27 S. P. Ravindranath, K. L. Henne, D. K. Thompson and J. Irudayaraj, ACS Nano, 2011, 5, 4729-4736.

28 A. Martín-Esteban, TrAC, Trends Anal. Chem., 2013, 45, 169181.

29 M. L. Yola, T. Eren and N. Atar, Sens. Actuators, B, 2015, 210, 149-157.

30 S. E. Diltemiz, R. Say, S. Büyüktiryaki, D. Hür, A. Denizli and A. Ersöz, Talanta, 2008, 75, 890-896.

31 S. Feng, F. Gao, Z. Chen, E. Grant, D. D. Kitts, S. Wang and X. Lu, J. Agric. Food Chem., 2013, 61, 10467-10475.

32 Y. Hu, S. Feng, F. Gao, E. C. Y. Li-Chan, E. Grant and X. Lu, Food Chem., 2015, 176, 123-129.

33 S. Dai, S. Wu, N. Duan and Z. Wang, Talanta, 2016, 158, 246253.

34 E. D. Asuquo and A. D. Martin, J. Environ. Chem. Eng., 2016, 4, 4207-4228.

35 B. Wei, C. Cai, B. Xu, Z. Jin and Y. Tian, Food Chem., 2018, 240, 165-173.

36 P. Liu, R. Liu, G. Guan, C. Jiang, S. Wang and Z. Zhang, Analyst, 2011, 136, 4152-4158.

37 Y. Hu and X. Lu, J. Food Sci., 2016, 81, N1272-N1280.

38 Y. Wang, S. Ren, H. Jiang, Y. Peng, J. Bai, Q. Li, C. Li, Z. Gao and B. Ning, RSC Adv., 2017, 7, 22215-22221.

39 Y. Tang, J. Gao, X. Liu, J. Lan, X. Gao, Y. Ma, M. Li and J. Li, Food Chem., 2016, 201, 72-79.

40 T. Janči, L. Mikac, M. Ivanda, N. Marušić Radovčić, H. Medić and S. Vidaček, J. Raman Spectrosc., 2017, 48, 64-72.

41 L. Luo, Z.-L. Xu, J.-Y. Yang, Z.-L. Xiao, Y.-J. Li, R. C. Beier, Y.-M. Sun, H.-T. Lei, H. Wang and Y.-D. Shen, J. Agric. Food Chem., 2014, 62, 12299-12308.

42 S. Jiang, Y. Peng, B. Ning, J. Bai, Y. Liu, N. Zhang and Z. Gao, Sens. Actuators, B, 2015, 221, 15-21.

43 Z. Xie, Y. Wang, Y. Chen, X. Xu, Z. Jin, Y. Ding, N. Yang and F. Wu, Food Chem., 2017, 230, 547-552. 